\title{
Plants emerging with promising nanoworld
}

\author{
Pushpa C. Tomar *, Tanya Kalra, Garima Ahuja, Sakshi Taneja \\ Manav Rachna International University, New Delhi, India
}

\begin{abstract}
In recent years nanotechnology has become one of the most important and exciting forefront fields in Physics, Chemistry, Engineering and Biology. It shows great promise for providing us in the near future with many breakthroughs that will change the direction of technological advances in a wide range of applications. Nanotechnologies are being spoken of as the driving force behind a new industrial revolution. Both private-and public-sector spending are constantly increasing. Scientists have raised concerns that the basic building blocks of nanotechnologies - articles smaller than one billionth of a meter - pose a potential new class of risk to health and the environment. In fact, all different scientific disciplines, including every single sector (such as nanomaterials, micro and nanomachines, micro and nanoelectronics), have their own paradigm. This is why innovations and industrial developments are profoundly different. However, these fields are strongly interlinked. It is therefore necessary to make our studies more interdisciplinary in order to enable us to understand the nanoworld.
\end{abstract}

Key words: nanotechnology, nanoparticles, nanoagrochemicals, nanoworld, nanomatrial

\section{Introduction}

Nanotechnology, a new emerging and fascinating field of science, permits advanced research in many areas. Moreover, nanotechnological discoveries could open up novel applications in the field of biotechnology and agriculture (Wang et al., 2016). Nanotechnology is a novel scientific approach that involves the use of materials and equipment capable of manipulating physical as well as chemical properties of a substance at molecular levels. In addition, such biotechnology involves using the knowledge and techniques of biology to manipulate molecular, genetic and cellular processes to develop products and services and is used in diverse fields from medicine to agriculture (Fakruddin et al., 2012). Nanotechnology is one of the most important tools in modern agriculture, and agri-food nanotechnology is expected to become a driving economic force in the near future, due to the increasing world population (Sekhon, 2014). Nanotechnology has been defined as relating to materials, systems and processes which operate at a scale of 100 nanometers (nm) or less (Mousavi et al., 2011). It has the potential to revolutionize the agricultural and food industries with new tools for the mole- cular treatment of diseases, rapid disease detection, and enhancement of the ability of plants to absorb nutrients etc. This technique could be applied in improving important crops by organizing and linking carbohydrates, lipids, proteins and nucleic acids to nanocrystals (Zheng et al., 2009).

\section{Nanoparticles/nanocomposites}

Nanomaterials, typically $0.2-100 \mathrm{~nm}$ in size, have a high surface-to-volume ratio (Ravishankar et al., 2011); this increases their interaction with microorganisms, which in turn improves their antimicrobial activity. Transmission electron microscopy (TEM), low-resolution TEM(LRTEM), and high-resolution TEM (HRTEM) have helped in the characterization of nanoparticles (NPs) and revolutionized their use in various elds. The chemical, electrical, mechanical, optical, magnetic, and electro-potential properties of NPs differ from those of their bulk materials. This may be attributed to their high surface-to-volume ratio (Hajipour et al., 2012; Whitesides, 2005). The physicochemical and biological properties of NPs can be manipulated to suit the desired application (Feynman, 1991; Ravishankar et al., 2011).

\footnotetext{
*Corresponding author: Manav Rachna International University, New Delhi, India; e-mail: pushpa.fet@mriu.edu.in
} 
NPs may be organic or inorganic; however, inorganic NPs are used more often owing to their ability to withstand adverse reaction conditions (Ravishankar et al., 2011). NPs have been used in optical, chemical, and biological elds. Their potential applications include many speci c areas such as superconductors, optical devices, catalysts, fuel cells, gene and drug delivery, cell and tissue imaging, and biosensors (Adibkia et al., 2007; Tiwari et al., 2011; Zinjarde, 2012; Bahrami et al., 2014; Dizaj et al., 2015). Moreover, NPs have antimicrobial properties and have potential for use in diagnostic immunoassays (Nam et al., 2003; Chen et al., 2008; Osterfeld et al., 2008). Several types of NPs, including various metal and metal oxides, have been developed and evaluated; examples include silver $(\mathrm{Ag})$, gold $(\mathrm{Au})$, silver oxide $\left(\mathrm{Ag}_{2} \mathrm{O}\right)$, zinc oxide $(\mathrm{ZnO})$, titanium dioxide $\left(\mathrm{TiO}_{2}\right)$, calcium oxide $(\mathrm{CaO})$, copper oxide $(\mathrm{CuO})$, magnesium oxide $(\mathrm{MgO})$, and silicon dioxide $\left(\mathrm{SiO}_{2}\right)$ (Dizaj et al., 2015). Nanoparticles can serve as "magic bullets", containing herbicides, chemicals, or genes, which target particular plant parts and release their content. Nanocapsules can enable effective penetration of herbicides through cuticles and tissues, allowing for slow and constant release of active substances (Perea-de-Lugue et al., 2009).

\section{Types of nanoparticles}

\section{Zinc oxide nanoparticles}

Zinc oxide is an inorganic compound with the molecular formula $\mathrm{ZnO}$. It is a white powder which is nearly insoluble in water. $\mathrm{ZnO}$ powder is widely used as an additive in numerous materials and products including ceramics, glass, cement, rubber (e.g. car tires), lubricants, paints, ointments, adhesives, plastics, sealants, pigments, foods (a source of $\mathrm{Zn}$ nutrient), batteries, ferrites, and fire retardants. In the Earth's crust, $\mathrm{ZnO}$ is present as zincite mineral, but for commercial purposes synthetically produced $\mathrm{ZnO}$ is mainly used. $\mathrm{A} \mathrm{ZnO}$ semiconductor has several unique properties such as good transparency, high electron mobility, a wide band gap and strong luminescence at room temperature (RT). These properties account for its applications in the transparent electrodes in a liquid crystal display and in energy-saving or heat-protecting windows and other electronic applications. Zinc oxide (wurtzite, p63m) is known as a wide band gap semiconductor with a band gap energy of $3.3 \mathrm{Ev}$ at RT (Sabir et al., 2014). Nowadays, the unique properties of nanomaterials have encouraged researchers to develop many simpler and inexpensive techniques to produce nanostructures of technologically important materials. Several metal oxide nanoparticles have been produced which have possible future applications. Among these, zinc oxide is considered to be one of the best exploited at nano dimensions. Its wide band gap and large excitonic binding energy have made zinc oxide important both for scientific and industrial applications (Wang et al., 2004). The effect of NPs on seed germination depends on the concentrations of NPs and varies from plant to plant. De la Rosa and co-workers (2013) sprayed different concentrations of $\mathrm{ZnO}$ NPs on different parts of cucumber, alfalfa and tomato, and found that only cucumber seed germination was enhanced. Raliya and co-workers (2013) reported that $\mathrm{ZnO}$ NPs induced a significant improvement in Cyamopsis tetragonoloba plant biomass, shoot and root growth, root area, chlorophyll and protein synthesis, rhizospheric microbial population, acid phosphatase, alkaline phosphatase and phytase activity in cluster bean rhizosphere.

\section{Gold nanoparticles (AuNPs)}

The properties of gold nanoparticles are different from those of its bulk form because bulk gold is a yellow solid inert in nature, while gold nanoparticles are a winered coloured solution and are reported to have antioxidant properties. Inter-particle interactions and the assembly of gold nanoparticle networks play key roles in the determination of the properties of these nanoparticles (Deb at al., 2011). Gold nanoparticles exhibit various sizes, ranging from $1 \mathrm{~nm}$ to $8 \mu \mathrm{m}$. AuNPs improve seed germination, the number of leaves, leaf area, plant height, chlorophyll content, and sugar content that lead to a higher crop yield in Gloriosa superba (Arora et al., 2012; Gopinath et al., 2014). AuNPs have a significant influence on seed germination and the anti-oxidant system in Arabidopsis thaliana and alter expression levels of several microRNAs that regulate various morphological, physiological, and metabolic processes in plants (Kumar et al., 2013). AuNPs induce toxicity in plants by inhibiting aquaporin function, a group of proteins that help in the transportation of a wide range of molecules including water (Shah et al., 2009). 


\section{Silver nanoparticles}

Silver dioxide nanoparticles are between $1 \mathrm{~nm}$ and $100 \mathrm{~nm}$ in size (Graf et al., 2003). Frequently described as being "silver", some are composed of a large percentage of silver oxide due to the high ratio of surface-tobulk silver atoms. Numerous shapes of nanoparticles can beconstructed depending on the application at hand. Commonlyusedare spherical silver nanoparticles but diamond, octagonal and thin sheets are also popular (Graf et al., 2003). Such an extremely large surface area permits coordination of a vast number of ligands. The properties of silver nanoparticles applicable to human treatments are under investigation in laboratory and animal studies assessing their potential efficacy, toxicity, and costs.

NPs have both positive and negative effects on plant growth and development. Recently, Krishnaraj and coworkers (2012) studied the effect of biologically synthesized AgNPs on the growth and metabolism of hydroponically grown Bacopa monnieri, and found that AgNPs significantly reduced seed germination and induced the synthesis of proteins and carbohydrates as well as decreased the total phenol contents and catalase and peroxidase activities. Also, biologically synthesized AgNPs enhanced seed germination and seedling growth of $\mathrm{Bos}^{-}$ wellia ovaliofoliolata trees (Savithramma et al., 2012). AgNPs also increased growth parameters (shoot and root length, leaf area) and biochemical attributes (chlorophyll, carbohydrate and protein contents, antioxidant enzymes) of Brassica juncea, common bean and corn (Salama, 2012; Sharma et al., 2012). However, Gruyer and co-workers (2013) reported that AgNPs exerted both positive and negative effects on root elongation, depending on the plant species. They reported that root length was increased in barley, but inhibited in lettuce. Also, Yin and co-workers (2012) studied the effects of AgNPs on germination of 11 wetland plant species (eg Lolium multiflorum). They found that GA-AgNPs had effects equal to or greater in magnitude than $\mathrm{AgNO}_{3}$ on seedling growth, confirming that the high toxicity of AgNPs is not only due to the ionic Ag content. We have also found that plant species differ in their susceptibility to AgNPs and $\mathrm{AgNO}_{3}$ and that AgNP toxicity to wetland plants under realistic growth conditions is only partially consistent with the results obtained from pure culture experiments. These results suggest that the increasing release of AgNPs into the environment could have an effect on wetland plant communities (Yin et al., 2012).
The impact of AgNPs on the morphology and physiology of plants depends on the size and shape of NPs. Syu and co-workers (2014) studied the effect of 3 different morphologies of AgNPs on physiological and molecular responses of Arabidopsis and suggested that decahedral AgNPs showed the highest degree of root growth promotion (RGP).

\section{Silicon dioxide nanoparticles}

Silicon dioxide nanoparticles, also known as silica nanoparticles or nanosilica, are the basis for a significant amount of biomedical research due to their stability, low toxicity and ability to be functionalized with a range of molecules and polymers. According to Suriyaprabha and co-workers (2012), nano- $\mathrm{SiO}_{2}$ increased seed germination by providing better nutrients availability to maize seeds, and $\mathrm{pH}$ and conductivity of the growing medium. Bao-shan and co-workers (2004) exogenously applied nano-SiO ${ }_{2}$ on Changbai larch (Larix olgensis) seedlings

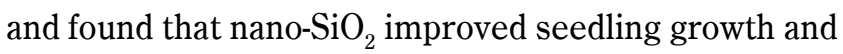
quality, including mean height, root collar diameter, main root length, and the number of lateral roots of seedlings, and also induced the synthesis of chlorophyll. It has also been shown that under abiotic stress, nano$\mathrm{SiO}_{2}$ augments seed germination. Haghighi and co-workers, (2012) and Siddiqui and co-workers (2014) reported that nano- $\mathrm{SiO}_{2}$ in tomato and in squash, respectively, enhanced seed germination and stimulated the antioxidant system under salt stress. $\mathrm{Nano}_{-} \mathrm{SiO}_{2}$ enhanced plant growth and development by increasing gas exchange and chlorophyll fluorescence parameters, such as the net photosynthetic rate, transpiration rate, stomatal conductance, Photosystem II (PSII) potential activity, effective photochemical efficiency, actual photochemical efficiency, electron transport rate and photochemical quenching (Siddiqui et al., 2015).

\section{Positive effects of nanotechnology in agriculture}

\section{Carbon nanotubes and plant growth}

The application of nanoparticles such as carbon nanotubes in agriculture has led to very promising results (Liu et al., 2015). Carbon nanotubes (CNTs) are arranged in single or multiple layers of carbon ions placed in a cylinder (Li et al., 1996; Philip et al., 2000; Hazarika et al., 2014; Liu et al., 2014). CNTs possess excellent tensile strength and are possibly the strongest, 
smallest fibers known (Mani et al., 2014; Hazarika et al., 2014; Liu et al., 2014). Their important role is derived from their competitive mechanical, electrical, thermal and chemical properties (Siddiqui et al., 2015). Carbonbased nanomaterials are being studied in order to understand the uptake and transport of nutrients into intact plant cells (Chai et al., 2013; Khodakovskaya et al., 2013; Long et al., 2012). CNTs can translocate to systemic sites, such as fruits, leaves and roots, which could involve a strong interaction with the cells of, for example, tomato seedlings. This results in significant changes in the total gene expression in fruits, leaves, and roots (Khodakovskaya et al., 2013). Moreover, the root number, root length, plantlet length and hairy root formation are enhanced.

Many different forms of CNTs are found. CNTs can be chemically modified and/or functionalized with either hydroxyl or carboxyl groups or another nanomaterial. Non-functionalized or pristine single-walled CNTs can be visualized as single sheets of graphite rolled up in the form of a cylinder with seamless ends. Its diameters range from $0.4 \mathrm{~nm}$ to $1 \mu \mathrm{m}$. Non-functionalized multiwalled CNTs consist of several single-walled CNTs stacked one inside another. Their diameters are up to $100 \mathrm{~nm}$ (Dresselhaus et al., 2001). CNTs improve root growth of cucumbers (Cucumis sativus) and onions (Allium cepa); importantly nanotube sheets are formed by both functionalized-CNTs and non-functionalized CNTs on their root surfaces (Canas et al., 2008; Ke et al., 2011). It has also been found that CNTs help organize nutrient absorption in plants (Taha et al., 2016). As has been shown, CNTs penetrate tomato seed coats and significantly enhance seedling growth and seed germination rates (Ke et al., 2011; Ghodake et al, 2010; Khodokovskaya et al., 2009). Also, carbon nanotubes could be used as nutrient carriers for macro and micro elements (Liu et al., 2015).

\section{Metal and metal oxide nanomaterials stimulate plant growth}

The estimated production of metal/metal oxide nanoparticles will probably rise (from 2000 tons in 2004) to over 58,000 tons yearly in the near future (Niederberger, 2007; Franke et al., 2006; Kolmakov et al., 2004). A large number of studies on the effects of metal oxide NPs on the germination and growth of plants have been documented. For example, nanosized TiO (Tita- nium dioxide) promoted plant growth when seeds were soaked or sprayed with NPs (Zheng et al., 2005) and root elongation was promoted by a large amount of Zinc oxide NPs ( $\mathrm{ZnO} \mathrm{NPs}$ ) in soybean (Lopez-Moreno et al., 2010). $\mathrm{TiO}_{2} \mathrm{NPs}_{\mathrm{s}}$ may be used for decomposing organic compounds and producing $\mathrm{H}_{2}$ as a fuel (Gupta et al., 2011). Moreover, a $58.2 \%$ and $69.8 \%$ increase in fresh and dry weights, and a significant increase in the chlorophyll content, the photosynthetic rate and Rubisco activity were recorded in spinach when treated with anatase (one of the 3 mineral forms of titanium dioxide) $\mathrm{TiO}_{2}$ NPs (Linglan et al., 2008).

\section{Antibacterial activity of metal oxide nanoparticles}

Several metal oxides in the form of nanoparticles have been reported to exhibit a marked antibacterial activity, allowing for efficient eradication of various bacterial strains. This fact has attracted significant interest from environmental, agricultural and health care industries that are searching for newer and better agents to control or prevent bacterial infections. Some distinctive antibacterial mechanisms have been proposed, which include reactive oxygen species (ROS) formation, metalion release, particle internalization into bacteria and direct mechanical destruction of bacterial cell walls and/or membranes. For instance, oxidative stress induced by $\mathrm{Ag}_{2} \mathrm{O}$ nanoparticles has been shown to damage the DNA of Escherichia coli which leads to the interruption of the bacterial cell cycle and induction of bacterial death (Sondi et al., 2004).

\section{Role of nanoparticles in photosynthesis}

Photosynthesis is a process by which plants convert solar energy into chemical energy. Only $2-4 \%$ of available radiation energy converted by plants is used for plant growth and development (Savithramma et al., 2012). Nanotechnology has the potential to improve the functioning of the photosynthetic machinery. Single-wall carbon nanotubes (SWCNTs) embedded in isolated chloroplasts lead to a three-fold increase in photosynthetic activity, compared to controls. It also increases the maximum electron transport rate (Giraldo et al., 2014). Silicon dioxide nanoparticles $\left(\mathrm{SiO}_{2} \mathrm{NPs}\right)$ increase the photosynthetic rate by changing the activity of carbonic anhydrase and the synthesis of photosynthetic pigments (Mahmoodzadeh et al., 2013; Jaberzadeh et al., 2013). $\mathrm{SiO}_{2} \mathrm{NPs}$ 
have been found to accelerate the growth and development of oat and lucerene by increasing the content of photosynthetic pigments in their leaves (Tereshchenko et al., 2017). Carbonic anhydrase supplies $\mathrm{CO}_{2}$ to RuBisCO which may improve photosynthesis (Siddiqui et al., 2012).

A nano mesoporous silica compound (SBA) bound with photosystem II increases the activity of photosynthetic oxygen evolving reactions (Noji et al., 2011). It has also been shown that metal nanoparticles can increase the efficiency of chemical energy production in photosynthetic systems (Govorov et al., 2007). Also, Noji and co-workers (2011) reported that a nano mesoporous silica compound (SBA) bound with photosystem II (PSII) induced stable activity in a photosynthetic oxygen-evolving reaction, indicating the light-driven electron transport from water to the quinone molecules. The authors suggested that PSII-SBA conjugates might have suitable properties as photosensors and artificial photosynthetic systems (Noji et al., 2011). Recently, Lin and co-workers (2014) developed genetically engineered tobacco plants by replacing the RuBisCO gene with 2 genes encoding the large and small subunits of the Se7942 enzyme form cyanobacterium Synechococcus elongatus (Lin et al., 2014). Such genetically modified (GMO) plants had a higher photosynthetic efficiency than non-GMO plants. These improved tobacco lines represent an important step towards improving photosynthesis in plants.

\section{Nanoparticles in disease suppression}

Viruses, bacteria, fungi and nematodes are the main organisms responsible for plant diseases resulting in decreased yields and poor quality of plant products. It has been reported that NPs can be used to suppress pathogens and thus increase crop growth (Singh et al., 2015). Since the physiochemical properties of nanoparticles vary greatly, it has become important to examine the effect of NPs on microorganisms in terms of plant protection, especially against phytopathogens, to harness the benefits of this technology. Due to the ultrasmall size of nanoparticles, which are even smaller than virus particles, as well as due to their high reactivity, nanoparticles may affect the activities of many microorganisms. In silver NPs, the colonization of Staphylococcus aureus, Pseudomonas aeruginosa, Escherichia coli and Klebsiella pneumonia is inhibited. The highest antimicrobial activity of silver nanoparticles $(30 \mathrm{~mm})$ synthesized by Solanum tricobatum and Ocimum tenuiflorum leaf extracts was found against $S$. aureus and E. coli, respectively. The combined activities of AgNPs with the fungicide flucanazole have been found to be effective against Candida albicans, Phoma glomerata and Trichoderma sp. (Gajbhiye et al., 2009). MgO NPs exhibit significant antimicrobial activity due to their strong interaction with the negatively charged surface of bacterial membranes (Huang et al., 2005). The antibacterial activity of $\mathrm{MgO}$ nanoparticles (NPs) was evaluated against the Gram-negative bacteria Escherichia coli and Pseudomonas aeruginosa as well as the Gram-positive bacterium Staphylococcus aureus.

\section{Negative effects of nanotechnology in agriculture on food}

The release of engineered nanoparticles may cause adverse effects on edible plants, as has been shown in radish, corn, and cucumber grass, lettuce and rape (Suppan, 2013).

The potential risks and benefits of using nanosilvers as antibacterial agents in consumer and health care products are being debated globally (Boholm et al., 2014). According to Wang and co-workers (2012), there is now some understanding of the long-term impact of cerium oxide nanoparticles on plants, health and their implications for food safety and security. The implication of $\mathrm{ZnO}$ NPs on wheat showed reduced biomass production as $\mathrm{Zn}^{2+}$ enters the plants and thereby affects the food chain (Prasad et al., 2017). There is a lack of regulatory harmonization, while the empirical data impede global strategies for products commercializing nanotechnologies (Chaudhry et al., 2008). Thus, there is an urgent need for the creation of regulatory systems capable of managing risks associated with nano foods and the use of nanotechnology in the food industry (Momin et al., 2013).

\section{Health threats}

NPs may cause potential health threats owing to their selective accumulation in different cells, tissues, and certain cellular structures (Buzea et al., 2007; Li et al., 2012). The majority of the NPs synthesized to date have the capacity to permeate membrane cells and spread to different regions in the body, such as blood vessels, nerve cells, and the lymphatic vascular system 
(Rudramurthy et al., 2016). NPs may escape the immune defence mechanism thanks to their small size and may cause inflammatory and/or toxic responses ( $\mathrm{Li}$ et al., 2012). Inhaled particles penetrate into the respiratory tract, where they target different anatomical sites, depending, among other properties, on their aerodynamic size. Particles are categorized according to their aerodynamic size to $\mathrm{PM}_{10}$, thoracic particles $(\leq 10 \mu \mathrm{m})$ and $\mathrm{PM}_{2.5}(\leq 2.5 \mu \mathrm{m})$, or fine fraction. The particles with a range of aerodynamic sizes between 10 and $2.5 \mu \mathrm{m}$ $\left(\mathrm{PM}_{10-2.5}\right)$ are known as the coarse fraction (Lital et al., 2010). If the aerodynamic size is equal to or smaller than $0.1 \mu \mathrm{m}$, the particles are called ultrafine particles (UFP), and one of the main sources of this type of primary particles is diesel exhaust (DEP) (Holgate et al., 2003).

\section{Inducing stress}

NPs with different composition, size, concentration, and physical/chemical properties have been reported to negatively influence the growth and development of various plant species. Ma and co-workers (2010) and Khodakovskaya and co-workers (2009) reported that multiwalled carbon nanotubes markedly influenced tomato seed germination and seedling growth by up-regulating stress-related gene expression. A root proteome study revealed that AgNP-responsive proteins were primarily associated with the oxidative stress response pathway, $\mathrm{Ca}^{2+}$ regulation and signaling, transcription, protein degradation, cell wall synthesis, cell division, and apoptosis (Vannini et al., 2013). An experiment performed on the nano- $\mathrm{CuO}$ (cupric oxide) modulating photosynthetic performance and antioxidative defense system in Hordeum vulgare demonstrated restrictions in root and shoot growth with a decreased photosynthetic performance index (Shaw et al., 2014). Also, NPs such as titanium oxide, zinc oxide, cerium oxide, and silver NPs were deposited on the surfaces of cells as well as in the organelles, which resulted in oxidative stress to the cell through the induction of oxidative stress signaling (Hossain et al., 2015). In rice, $\mathrm{ZnO}$ NPs caused deleterious effects on root length at early growth stages (Boonyanitipong et al., 2011). Changes in enzyme activities, ascorbate and free thiol levels resulting in higher membrane damage and the photosynthetic stress have been documented in shoots of germinating rice seedlings exposed to $500 \mathrm{mgl}^{-1}$ of cerium oxide NPs (Rico et al., 2013). Moreover, nano-CuO mediated DNA damage and plant growth restrictions have been reported in radish (Raphanus sativus) and ryegrass (Lolium perenne and Lolium rigidum) (Atha et al., 2012).

\section{Applications of nanoparticles}

\section{Nanopesticides and nanofertilizers (nano agrochemicals)}

This section focuses on applications of nanotechnology for plant protection and nutrition, in the form of nanopesticides or nanofertilizers, later referred to as nano agrochemicals. The use of agrochemicals is crucial to modern agriculture. The use of nanotechnology in agriculture has become more popular over the past decade, with a particular interest in developing novel nano agrochemicals in the form of so-called "nanopesticides" and "nanofertilizers". The terms "nanopesticide" and "nanofertilizer" have been extensively used, but sometimes with very different meanings. Inventories presented to date and based on patent analysis and the scientific literature (Gogos et al., 2012; Kah et al., 2013) indicate that the terms can designate a very wide range of products in terms of their size, nature, level of development and even relevance for agricultural practices. In the scientific literature, the prefix "nano" has been associated until now with the notion of novelty and implicitly suggests superior properties relative to non-nano counterparts. Hence, many formulations have been named "nano" with the main objective of increasing attention and possibly facilitating publication. When information makes its way to a non-specialist readership (e.g. in press releases, interviews, reports), there is a risk of confusion about what nanopesticides or nanofertilizers are and how they relate, for instance, to the definitions that have been proposed for regulatory purposes (Kah, 2015).

\section{Recycling agricultural waste}

Nanotechnology may also be applied to prevent waste production in agriculture, particularly in the cotton industry. When cotton is processed into a fabric or garment, some of the cellulose or the fibers are discarded as wastes or used for the production of low-value products such as cotton balls, yarns and cotton batting. With the use of newly-developed solvents and a technique called electrospinning, scientists can produce 100 $\mathrm{nm}$ diameter fibers that can be used as fertilizers or pesticide absorbents. These high-performance absorbents 
allow for targeted application at desired times and locations (Lang, 2003). A viable option for the production of biofuels is presented by cellulosic feedstocks. Moreover, nanotechnology can enhance the performance of enzymes used in the conversion of cellulose into ethanol, as scientists are working on nano-engineered enzymes that will allow the simple and cost-effective conversion of cellulose from plant-part wastes into ethanol.

Also, rice husks, a rice-milling byproduct, can be used as a source of renewable energy. When rice husks are turned into thermal energy or biofuel, a large amount of high-quality nanosilica is produced which can be further utilized in making other materials such as glass and concrete (Liou et al., 2010).

\section{Nanosensors and nanotech delivery systems for pests, nutrients and plant hormones}

Nanosensors and nano-based smart delivery systems could help in the efficient use of agricultural natural resources such as water, nutrients and chemicals through precision farming. Through the use of nanomaterials and global positioning systems with satellite imaging of fields, farm managers could remotely detect crop pests or evidence of stresses such as drought. Once a pest or drought is detected, there would be an automatic adjustment of pesticide applications or irrigation levels. Nanosensors dispersed in the field could potentially also detect the presence of plant viruses and the levels of soil nutrients. Nano-encapsulated slow release fertilizers have also become a trend to save fertilizer consumption and to minimize environmental pollution (Jones, 2006).

Nanobarcodes and nanoprocessing could be used to monitor the quality of agricultural produce. Scientists at Cornell University have used the concept of grocery barcodes for cheap, efficient, rapid and easy decoding and detection of diseases (Pocket K., 2011). They produced microscopic probes or nanobarcodes that could tag multiple pathogens on a farm which can easily be detected using any fluorescent-based equipment. This on-going project generally aims at developing a portable on-site detector which can be used by non-trained individuals.

Through nanotechnology, scientists are also able to study plant regulation of hormones such as auxins, which are responsible for root growth and seedling establishment. Scientists at Purdue University have developed a nanosensor that reacts with auxins (Pocket K., 2011). The interaction between the auxins and the nanosensor generated an electrical signal which was the basis for measuring auxin concentration at a particular point. The nanosensor oscillated taking auxin concentration readings at various points of the root. A system of formulas then verified if the auxin was absorbed or released by the surrounding cells. This is a breakthrough in auxin research, because it helps scientists to understand how plant roots adapt to their environment, especially in marginal soils (McLamore et al., 2010).

\section{Biosensors}

\section{Rapid detection biosensors}

Biosensors are instruments able to reduce the time required for lengthy microbial testing. Microorganisms can be integrated into sensors with a variety of transducers, such as amperometric, potentiometric, conductimetric, luminescence and fluorescence, to construct biosensor devices (Touhami, 2014). Since the microbial biosensor response, the operational stability and their longterm use are, to some extent, a function of the immobilization strategy used, the immobilization technology plays a very important role and the choice of the immobilization technique is critical. A potentiometric biosensor based on a $\mathrm{pH}$ electrode modified by permeable $P$. aeruginosa has been developed for selective and rapid detection of cephalosporin group of antibiotics (Kumar et al., 2008). The hydrolysis of cephalosporin, due to the enzyme activity of the microbial layer, is accompanied by the production of protons near the $\mathrm{pH}$ electrode. The response will come from the change of the electric potential difference between the working electrode and the reference electrode (Ferrini et al., 2008). Other applications of these instruments include the detection of contaminants in different bodies such as water supplies, raw food materials and food products (Ditta, 2012).

\section{Enzymatic biosensors}

Enzymes can act as sensing elements as they are very specific in their attachment to certain biomolecules. A wide range of amperometric enzyme electrodes, differing in electrode design or material, immobilization approach, or membrane composition, have been described. The first developed glucose enzyme electrode relied on a thin layer of glucose oxidase (GOx) entrapped over an oxygen electrode via a semi-permeable dialysis membrane (Touhami, 2014). Measurements have been 
made based on the monitoring of the oxygen consumed by the enzyme-catalyzed reaction (Wang, 2008). The entire field of biosensors can trace its origin to this original glucose enzyme electrode.

\section{Nanomaterials for energy conversion}

One of the most interesting and most flexible renewable energy technologies is the direct conversion of sunlight into electric power called the photovoltaic effect (Dai et al., 2012; Lewis, 2007). Carbon nanomaterials, including $\mathrm{C}_{60}$ fullerenes (Sariciftci et al., 1992; He et al., 2011), carbon nanotubes (CNTs) (Hecht et al., 2011; Somani et al., 2007) and graphene (Novoselov et al., 2004; Luo et al., 2012), have been studied and shown to be extremely efficient electron acceptors in polymer and quantum dot solar cells (Dai et al., 2012). Relatively new, dye sensitized solar cells are of great promise. In these devices, a nanocrystalline mesoporous titanium dioxide $\left(\mathrm{TiO}_{2}\right)$ film, with a monolayer of the charge transfer dye attached to its surface, is pasted on a transparent conductive substrate (Hagfeldt et al., 2010; Hagfeldt, 2012). The large NM surface area for dye chemisorptions and the short charge migration length underlie their power conversion efficiency (Chen et al., 2012; Zukalová et al., 2005). In addition to solar cells, nanotechnology has made a big impact on fuel cells: devices able to convert chemical energy directly into electricity (Chen et al., 2012). Nano-porous metals with a high surface area, low specific densities and rich surface chemistry can serve as highly efficient electro-catalysts for the critical electrode oxidation/reduction reactions in fuel cells (Zhang et al., 2012; Qiao et al., 2011). Platinum nanoparticles (Pt NPs) have been regarded as the best cell catalysts, although the Pt-based electrode suffers from a time-dependent drift and carbon monoxide deactivation (Zhong et al., 2010). In this regard, because of their higher electro-catalytic activities and greater resistance, nano-sized multi (bi-tri)-metallic Pt alloys have been the object of further exploration (Wang et al., 2009; Mazumder et al., 2010). Interestingly, CNTs and graphene, initially used in fuel cells as attractive materials for catalyst supports with the aim of lowering the precious-metal loading and enhancing catalyst activity and durability, have also been studied as metal-free catalysts in fuel cells (Antolini, 2009; Yu et al., 2010; Qu et al., 2013a). Their advantages rest in their high surface area, mesoporosity, good electrical conductivity, higher me- chanical strength, light weight and superb corrosion resistance (Qiao et al., 2011). Another important future energy option is the use of hydrogen gas as a source of clean fuel for many applications (Chen et al., 2010). Semiconductor NMs, e.g. $\mathrm{TiO}_{2}$ and cadmium sulfide nanostructures, have been studied as efficient catalysts for water conversion into oxygen and hydrogen (Chen et al., 2011; Wu et al., 2011; Li et al., 2009). Moreover, nano-structured carbons, metal-organic frameworks and polymers (Zuttel et al., 2002; Hirscher et al., 2003; Rosi et al., 2003; Germain et al., 2009) as well as metal hydrides and related complex hydrides (Orimo et al., 2007; Jeon et al., 2011) are examples of NMs investigated for hydrogen storage and transportation for high hydrogen capacity and minimal deterioration during hydrogenation.

\section{Nanomaterials for energy storage}

Nanotechnology may have a profound influence on electrical storage technologies, i.e. batteries and electrochemical super capacitors (Zhao et al., 2011). Redox-based super capacitors with nano-structured electrode materials have shown the potential to combine the high energy density of conventional batteries with the high power capabilities of electrostatic capacitors at the lab scale. Mixed metal oxides, e.g. ruthenium oxide $\left(\mathrm{RuO}_{2}\right)$, manganese oxide $\left(\mathrm{MnO}_{2}\right)$, magnetite $\left(\mathrm{Fe}_{3} \mathrm{O}_{4}\right)$ (Ke et al., 2005; Hu et al., 2006; Yu et al., 2008), CNTs (Dai et al., 2012; Kaempgen et al., 2009), graphene (Kim et al., 2011; Huang et al., 2012) and carbon metal oxide composites (Zhi et al., 2013), have been investigated as electrode NMs aimed at a high specific capacity and rate capability (Liu et al., 2008a; Liu et al., 2008b). Concerning rechargeable lithium batteries, the energy densities and the performances of these devices largely depend on the physical and chemical properties of the electrode material (Liu et al., 2010). In this regard, the reduced dimensions and the high surface area of NMs increase the rate of electron transport and the electrode-electrolyte contact, respectively, while the nano-structure itself provides facile strain relaxation and resistance to fracture (Chen et al., 2012). For anode applications, CNTs (Dai et al., 2012; Frackowiak et al., 2002; Centi et al., 2011), series of graphenebased nanostructures (Luo et al., 2012; Lian et al., 2010; Guo et al., 2009) and silicon nanowires (Chan et al., 2008) have been studied as promising host-high capacity materials and conductive additives. 


\section{Nanomaterials for water clean-up technologies}

Nanotechnology-enabled water and wastewater treatment promises not only to overcome major challenges faced by existing treatment technologies, but also to provide new treatment capabilities that could allow economic utilization of unconventional water sources to expand the water supply (Qu et al., 2013b). Interesting applications may include the incorporation of functional $\mathrm{NMs}$, such as metal-oxide NPs (aluminium oxide, $\mathrm{TiO}_{2}$ and zeolite) (Bae et al., 2005; Maximous et al., 2010; Pendergast et al., 2010), antimicrobial NMs (silver NPs (Ag NPs) and CNTs) (Hossain et al., 2013) and photocatalytic NMs (bimetallic-NPs, $\mathrm{TiO}_{2}$ ) (Chin et al., 2006; $\mathrm{Wu}$ et al., 2008), into membranes in order to improve their permeability, fouling resistance, biofilm control, mechanical and thermal stability, as well as to provide pollutant degradation and self-cleaning ability ( $\mathrm{Qu}$ et al., 2010). Moreover, CNTs, fullerene and metal-based nanoadsorbents may offer a significant improvement in the adsorption capacity of organic molecules, metal ions and heavy metals (Sharma et al., 2009; Ali., 2012; Hua et al., 2012; Gupta et al., 2013,). Interestingly, due to their NM-unique electrochemical, optical, and magnetic properties, research has been conducted into the development of nano-enabled pathogen sensors, both cells and biomolecules (Vikesland et al., 2010; Theron et al., 2010).

\section{Nanobarcodes}

Biological applications of nanobarcodes

Nanobarcodes have been used as ID tags for a multiplexed analysis of gene expression and intracellular histopathology (Ditta, 2012). Improvements in plant resistance to various environmental stresses such as drought, salinity, and diseases have been possible through advances in the field of biotechnology, also at the nanoscale. More effective identification and utilization of plant gene trait resources is expected to introduce a rapid and cost-effective capability through advances in nanotechnology-based gene sequencing (Branton, 2008).

\section{Non-biological applications of nanobarcodes}

Nanobarcodes serve as uniquely identifiable nanoscale tags and have been applied for non-biological applications, such as for authentication or tracking in agricultural food and husbandry products. This nanobarcode technology will enable the development of new auto-ID technologies for the tagging of items previously not practicable to tag with conventional barcodes (Ditta, 2012).

\section{Photocatalysis}

One of the processes where nanoparticles have been used for several decades now is photocatalysis (Blake, 1997). This is a combination of 2 words: "photo" meaning "light" and "catalysis" meaning "a reaction caused by a catalyst". So, it involves the reaction of a catalyst (nanoparticles) with chemical compounds in the presence of light. When nanoparticles of specific compounds are subjected to UV light, the electrons in the outermost shell (valence electrons) are excited, which results in the formation of electron hole pairs, i.e. negative electrons and positive holes. These are excellent oxidizing agents and include metal oxides such as $\mathrm{TiO}_{2}$ (Bhatkhande et al., (2001), $\mathrm{ZnO}$ (Li et al., 2003), and $\mathrm{SnO}_{2}$ (Ko et al.,2009), as well as sulfides such as $\mathrm{ZnS}$ (Feigl et al., 2010). Due to their large surface-to-volume ratio, these nanoparticles have very efficient rates of degradation and disinfection. As the size of particles decreases, the number of surface atoms is increased, which results in a tremendous increase in chemical reactivity and other physico-chemical properties related to certain specific conditions such as photocatalysis, photoluminescence, etc. (Ditta, 2012). Thus, this process can be used for the decomposition of many toxic compounds such as pesticides, which take a long time to degrade under normal conditions (Malato et al., 2002).

\section{Desalination}

Due to limited resources of fresh water, it is likely that in the near future, desalination of sea water will become a major source of fresh water. Conventional desalination technologies such as reverse osmosis (RO) membranes are currently being used, but these are costly due to the large amount of energy required (Ditta, 2012). Nanotechnology has played a very important role in the development of a number of low-energy alternatives, among which 3 are most promising: 1) proteinpolymer biomimetic membranes, 2) aligned-carbon nanotube membranes and 3) thin film nanocomposite membranes (Hoek et al., 2009). These technologies have shown up to 1000 times better desalination efficiencies than RO, as these have higher water permeability due to 
the presence of carbon nanotube membranes in their structure.

\section{Conclusion and prospects}

Nanotechnology has great potential, as it can enhance the quality of life through its applications in various fields such as agriculture and the food industry. Around the world it has become the future of every nation. However, we must be very careful with any new technology to be introduced due to the possible unforeseen risks that may come with their use. Nonetheless, it is also critical for the future of our world to produce a workforce trained in nanotechnology. In this process, the first step is to inform the public about the advantages of nanotechnologies, which, as we foresee, will result in a tremendous increase in the interest and discovery of new potential applications in all domains. It is with this in mind that this review has been written. The goal of the paper is the dissemination of basic knowledge about the applications of nanotechnology in agriculture and their prospects in the near future with reference to the current situation around the world. This review has identified some of the potential agricultural applications of nanotechnology for the welfare of humans and for sustainable environment, challenges and opportunities for developing countries. Finally, for the full implementation of such technology, collaboration between developed and developing countries, public and private sectors and between research institutions and international organizations is required. The future of nanotechnology is uncertain for many reasons, such as the negative reaction of the public towards genetically modified crops, the lack of the requisite skills in public agricultural research organizations for this type of research and illequipped and somewhat hesitant regulatory structures to deal with these new technologies. There is a pressing need to remove the sharp boundary present between the social and natural sciences and if we succeed in doing so, we may be able to develop a more desirable and more democratic socio-technical future.

\section{References}

Adibkia K., Omidi Y., Siahi M.R., Javadzadeh A.R., BarzegarJalali M., Barar J., Maleki N., Mohammadi G., Nokhodchi A. (2007) Inhibition of endotoxin-induced uveitis by methylprednisolone acetate nanosuspension in rabbits. J. Ocul. Pharmacol. Ther. 23: 421-432.
Ali I. (2012) New generation adsorbents for water treatment. Chem. Rev. 112: 5073-5091.

Antolini E. (2009) Carbon supports for low-temperature fuel cell catalysts. Appl. Catal. B: Environ. 88: 1-24.

Arora S., Sharma P., Kumar S., Nayan R., Khanna P.K., Zaidi M.G.H. (2012) Gold nanoparticle induced enhancement in growth and seed yield of Brassica juncea. Plant Growth Regul. 66: 303-310.

Atha D.H., Wang H., Petersen E.J., Cleveland D., Holbrook R.D., Jaruga P., Dizdaroglu M., Xing B., Nelson B.C. (2012) Copper oxide nanoparticle mediated DNA damage in terrestrial plant models. Environ. Sci. Technol. 46: 1819-1827.

Bae T.H., Tak T.M. (2005) Effect of TiO2 nanoparticles on fouling mitigation of ultrafiltration membranes for activated sludge filtration. J. Membr. Sci. 249: 1-8.

Bahrami K., Nazari P., Nabavi M., Golkar M., Almasirad A., Shahverdi A.R. (2014) Hydroxyl capped silver-gold alloy nanoparticles: Characterization and their combination effect with different antibiotics against Staphylococcus aureus. Nanomed. J. 1: 155-161.

Bao-shan L., Shao-qi D., Chun-hui L., Li-jun F., Shu-chun Q., Min Y. (2004) Effect of TMS (nanostructured silicon dioxide) on growth of Changbai larch seedlings. J. Forest Res. 15: 138-140.

Bhatkhande D.S., Pangarkar V.G., Beenackers A.A.C.M. (2001) Solar-assisted photochemical and photocatalytic degradation of phenol. J. Chem. Technol. Biotechnol. 76: 363-370.

Blake D.M. (1997) Bibliography of Work on the Photocatalytic Removal of Hazardous Compounds from Water and Air number. (Golden, Co: National Renewable Energy Laboratory) NREL/TP-473-22197.

Boholm M., Arvidsson R. (2014) Controversy over antibacterial silver: implications for environmental and sustainability assessments. J. Clean Prod. 68: 135-143.

Boonyanitipong P., Kositsup B., Kumar P., Baruah S., Dutta J. (2011) Toxicity of $\mathrm{ZnO}$ and TiO2 nanoparticles on germinating rice seed Oryza sativa L. Int. J. Biosci. Biochem. Bioninform. 21: 282-285.

Branton D. (2008) The potential and challenges of nanopore sequencing. Nature Biotechnol. 26: 1146-1153.

Buzea C., Pacheco II., Robbie K. (2007) Nanomaterials and nanoparticles: Sources and toxicity. Biointerphases 2: 17-71.

Canas J.E., Long M., Nations S. (2008) Effects of functionalized and nonfunctionalized single-walled carbon nanotubes on root elongation of select crop species. Environ. Toxicol. Chem. 27(9): 1922-1931.

Centi G., Perathoner S. (2011) Carbon nanotubes for sustainable energy applications. Chem. Sus. Chem. 4: 913-925.

Chai M., Shi F., Li R., Liu L., Liu Y., Liu F.(2013) Interactive effects of cadmium and carbon nanotubes on the growth and metal accumulation in a halophyte Spartina alterniflora (Poaceae). Plant Growth Regul. 71(2): 171-179.

Chan C.K., Peng H., Liu G., McIlwrath K., Zhang X.F., Huggins R.A., Cui Y. (2008) High-performance lithium battery anodes using silicon nanowires. Nat. Nanotechnol. 3: 31-35. 
Chaudhry Q., Scotter M., Blackburn J., et al. (2008) Applications and implications of nanotechnologies for the food sector. Food Addit. Contam. Part A: Chem. Anal. Control Expo Risk Assess. 25(3): 241-258.

Chen H., Kou X., Yang Z., Ni W., Wang J.(2008) Shape and size-dependent refractive index sensitivity of gold nanoparticles. Langmuir 24: 5233-5237.

Chen X., Li C., Grätzel M., Kostecki R., Mao S.S. (2012) Nanomaterials for renewable energy production and storage. Chem. Soc. Rev. 41: 7909-7937.

Chen X., Shen S., Guo L., Mao S.S. (2010) Semiconductorbased photocatalytic hydrogen generation. Chem. Rev. 110: 6503-6570.

Chen X., Liu L., Yu P.Y., Mao S.S. (2011) Increasing solar absorption for photocatalysis with black hydrogenated titanium dioxide nanocrystals. Science 331: 746-750.

Chin S.S., Chiang K., Fane A.G.(2006) The stability of polymeric membranes in a TiO2 photocatalysis process. J. Membrane Sci. 275: 202-211.

Dai L.,Chang D.W., Baek J.B., Lu W. (2012) Carbon nanomaterials for advanced energy converse on and storage. Small 8: 1130-1166.

De la Rosa G., Lopez-Moreno M.L., de Haro D., Botez C.E., Peralta-Videa J.R., Gardea-Torresdey J.L. (2013) Effects of $\mathrm{ZnO}$ nanoparticles in alfalfa, tomato, and cucumber at the germination stage: root development and $X$-ray $a b$ sorption spectroscopy studies. Pure Appl. Chem. 85(12): 2161-2174.

Deb S., Patra H.K., Lahiri P, Dasgupta A.K., Chakrabarti K., Chaudhuri U.(2011) Multistability in platelets and their response to gold nanoparticles. Nanomed. Nanotech. Biol. Med. 7: 376-384.

Ditta A. (2012) How helpful is nanotechnology in agriculture? Adv. Nat. Sci.: Nanosci. Nanotechnol. 3: 033002.

Dizaj S.M., Mennati A., Jafari S., Khezri K., Adibkia K. (2015) Antimicrobial activity of carbon-based nanoparticles. Adv. Pharm. Bull. 5: 19-23.

Dresselhans M.S., Dresselhaus G., Avouris P. ed. (2001) Carbon nanotubes: Synthesis, structure, properties and applications. Springer Berlin.

Fakruddin Md., Hossain Z., Afroz H. (2012) Prospects and applications of nanobiotechnology: a medical perspective. J. Nanobiotechnol. 10: 31.

Feigl C., Russo S. P., Barnard A.S. (2010) Safe, stable and effective nanotechnology: phase mapping of $\mathrm{ZnS}$ nanoparticles. J. Mater. Chem. 20: 4971.

Ferrini A.M., Mannoni V., Carpico G., Pellegrini G.E. (2008) Detection and identification of beta-lactam residues in milk using a hybrid biosensor. J. Agric. Food Chem. 56: 784-788.

Feynman R. (1991) There's plenty of room at the bottom. Science 254: 1300-1301.

Frackowiak E., Beguin F. (2002) Electrochemical storage of energy in carbon nanotubes and nanostructured carbons. Carbon 40: 1775-1787.
Franke M.E., Koplin T.J., Simon U.(2006) Metal and metal oxide nanoparticles in chemiresistors: Does the nanoscale matter?"Small 2: 36-50.

Gajbhiye M., Kesharwani J., Ingle A., Gade A., Rai M. (2009) Fungus-mediated synthesis of silver nanoparticles and their activity against pathogenic fungi in combination with fluconazole. Nanomed-Nanotechnol. 5: 382-386.

Germain J., Fréchet J.M., Svec F. (2009) Nanoporous polymers for hydrogen storage. Small 5: 1098-1111.

Ghodake G., Seo Y.D., Park D., Lee D.S. (2010) Phytotoxicity of carbon nanotubes assessed by brassica juncea and phaseolus mungo. J. Nanoelectr. Optoelectr. 5: 157-160.

Giraldo J.P., Landry M.P., Faltermeier S.M., McNicholas T.P., Iverson N.M., Boghossian A.A., Reuel N.F., Hilmer A.J., Sen F., Brew J.A., Strano M.S. (2014) Plant nanobionics approach to augment photosynthesis and biochemical sensing. Nat. Mater. 13: 400-408.

Gogos A., Knauer K., Bucheli T.D. (2012) Nanomaterials in plant protection and fertilization: current state, fore seen applications, and research priorities. J. Agric. Food Chem. 60: 9781-9792.

Gopinath K., Gowri S., Karthika V., Arumugam A. (2014) Green synthesis of gold nanoparticles from fruit extract of Terminalia arjuna, for the enhanced seed germination activity of Gloriosa superba. J. Nanostruct. Chem. 4: 1-11.

Govorov A.O., Carmeli I. (2007) Hybrid structures composed of photosynthetic system and metal nanoparticles: plasmon enhancement effect. Nano Lett. 7: 620-625.

Graf C., Vossen Dirk L.J., Imhof Arnout. (2003) A general method to coat colloidal particles with silica. Langmuir 19(17): 6693-6700.

Gruyer N., Dorais M., Bastien C., Dassylva N., Triffault-Bouchet G. (2013) Interaction between silver nanoparticles and plant growth. Acta Hortic. 1037: 795-800.

Guo P., Song H., Chen X. (2009) Electrochemical performance of grapheme nanosheets as anode material for $1 \mathrm{i}$ thium-ion batteries. Electrochem. Commun. 11: 1320 -1324 .

Gupta V.K., Saleh T.A. (2013) Sorption of pollutants by porous carbon, carbon nanotubes and fullerene - an overview. Environ. Sci. Pollut. Res. Int. 20: 2828-2843.

Gupta S.M., Tripathi M. (2011) A review of TiO2 nanoparticles. Chin. Sci. Bull. 56: 1639-1657.

Hagfeldt A., Boschloo G., Sun L., Kloo L., Pettersson H. (2010) Dye-sensitized solar cells. Chem. Rev. 110: 6595 $-6663$.

Hagfeldt A. (2012) Brief overview of dye-sensitized solar cells. Ambio. 41(Suppl 2): 151-155.

Haghighi M., Afifipour Z., Mozafarian M. (2012) The effect of $\mathrm{N}$-Si on tomato seed germination under salinity levels. J. Biol. Environ. Sci. 6: 87-90.

Hajipour J.M., Fromm K.M., Ashkarran A.A., de Aberasturi D.J., de Larramendi I.R., Rojo T., Serpooshan V., Parak W.J., Mahmoudi M. (2012) Antibacterial properties of nanoparticles. Trend Biotechnol. 30: 499-511. 
Hazarika A., Maji TK. (2014) Strain sensing behavior and dynamic mechanical properties of carbon nanotubes/nanoclay reinforced wood polymer nanocomposite. Chem. Eng. J. 247: 33-41.

He Y., Li Y. (2011) Fullerene derivative acceptors for high performance polymer solar cells. Phys. Chem. Chem. Phys. 13: $1970-1983$.

Hecht D.S., Hu L., Irvin G. (2011) Emerging transparent electrodes based on thin films of carbon nanotubes, graphene, and metallic nanostructures. Adv. Mater. 23: 1482-1513.

Hirscher M., Becher M. (2003) Hydrogen storage in carbon nanotubes. J. Nanosci. Nanotechnol. 3: 3-17.

Hoek E.M.V., Ghosh A.K. (2009) Nanotechnology-based membranes for water purification. [in:] Nanotechnology applications for clean watered $N$ savage. Ed. M. Diallo, J. Duncan, A. Street, R. Sustich. Norwich (NY): William Andrew Inc., chapt. 4: 47.

Holgate S.T., Sandstrom T., Frew A.J., Stenfors N., Nordenhall C., Soderberg M. (2003) Health effects to acute exposure to air pollution. Part I: Healthy and arthmatic subjects exposed to diesel exhaust. Res. Rep. Health Eff. Inst. 112: 1-30.

Hossain F., Perales-Perez O.J., Hwang S., Román F. (2013) Antimicrobial nanomaterials as water disinfectant: applications, limitations and future perspectives. Sci. Total Environ. 466-467: 1047-1059.

Hossain Z., Mustafa G., Komatsu S. (2015) Plant responses to nanoparticle stress. Int. J. Mol. Sci. 16(11): 26644-26653.

Hu C.C., Chang K.H., Lin M.C., Wu Y.T. (2006) Design and tailoring of the nanotubular arrayed architecture of hydrous $\mathrm{RuO} 2$ for next generation supercapacitors. Nano Lett. 6: 2690-2695.

Hua M., Zhang S., Pan B., Zhang W., Lv L., Zhang Q. (2012) Heavy metal removal from water/wastewater by nanosized metal oxides: a review. J. Hazard Mater. 211-212: 317 $-331$.

Huang L., Li D.Q., Lin Y.J., Wei M., Evans D.G., Duan X. (2005) Controllable preparation of nano- $\mathrm{MgO}$ and investigation of its bactericidal properties. J. Inorg. Biochem. 99(5): 986-993.

Huang Y., Liang J., Chen Y. (2012) An overview of the applications of graphene-based materials in supercapacitors. Small 8: 1805-1834.

Jeon K.J., Moon H.R., Ruminski A.M., Jiang B., Kisielowski C., Bardhan R., Urban J.J. (2011) Air-stable magnesium nanocomposites provide rapid and high-capacity hydrogen storage without using heavy-metal catalysts. Nat. Mater. 10 : 286-290.

Jones P. (2006) A Nanotech Revolution in Agriculture and the Food Industry. http://www.understandingnano.com/fuel. html.

Kaempgen M., Chan C.K, Ma J., Cui Y., Gruner G. (2009) Printable thin film supercapacitors using single-walled carbon nanotubes. Nano Lett. 9: 1872-1876.

Kah M. (2015) Nanopesticides and nanofertilizers: emerging contaminants or opportunities for risk mitigation? Frontchem. 3: 64 .
Kah M., Beulke S., Tiede K., Hofmann T. (2013) Nanopesticides: state of knowledge, environmental fate and exposure modelling. Crit. Rev. Environ. Sci. Technol. 43: 1823 $-1867$.

Ke P., Lamm M.H. (2011) A biophysical perspective of understanding nanoparticles at Large. Phys. Chem. Chem. Phys. 13: 7273-7283.

Ke Y.F., Tsai D.S., Huang Y.S. (2005) Electrochemical capacitors of RuO2 nanophase grown on LiNbO3(100) and sapphire(0001) substrates. J. Mater. Chem. 15: 2122-2127.

Khodakovskaya M., Dervishi E., Mahmood M. (2009) Carbon nanotubes are able to penetrate plant seed coat and dramatically affect seed germination and plant growth. ACS Nano. 3(10): 3221-3227.

Khodakovskaya M.V., Kim B., Kim JN. (2013) Carbon nanotubes as plant growth regulators: effects on tomato growth, reproductive system, and soil microbial community. Small 9(1): 115-123.

Kim T.Y., Lee H.W., Stoller M., Dreyer D.R., Bielawski C.W., Ruoff R.S., Suh K.S. (2011) High-performance supercapacitors based on poly(ionic liquid)-modified graphene electrodes. ACS Nano. 5: 436-442.

Ko Y., Kang J., Park J., Lee S., Kim D. (2009) How helpful is nanotechnology in agriculture? Nanotechnology 3: 2043 -6262 .

Kolmakov A., Moskovits M. (2004) Chemical sensing and catalysis by one-dimensional metal-oxide nanostructures. Ann. Rev. Mater. Res. 34: 151-180.

Krishnaraj C., Jagan E.G., Ramachandran R., Abirami S.M., Mohan N., Kalaichelvan P.T. (2012) Effect of biologically synthesized silver nanoparticles on Bacopa monnieri (Linn.) Wettst. Plant Growth Metab. Process Biochem. 47(4): 651-658.

Kumar S., Kundu S., Pakshirajan K., Dasu V.V. (2008) Cephalosporins determination with a novel microbial biosensor based on permeabilized Pseudomonas aeruginosa whole cells. Appl. Biochem. Biotechnol. 151: 653-664.

Kumar V., Guleria P., Kumar V., Yadav S.K. (2013) Gold nanoparticle exposure induces growth and yield enhancement in Arabidopsis thaliana. Sci. Total Environ. 461-462: $462-468$

Lang S. (2003) Waste fiber can be recycled into valuable products using new technique of electrospinning. Cornell Res. Rep.: Cornell Univ.

Lewis N.S. (2007) Toward cost-effective solar energy use. Science 315: 798-801.

Li D., Haneda H. (2003) Morphologies of zinc oxide particles and their effects on photocatalysis. Chemosphere 51: 129137.

Li W.Z., Xie S.S., Qian L.X. (1996) Large-scale synthesis of aligned carbonnanotubes. Science 274(5293): 1701-1703.

Li X., Wang L., Fan Y., Feng Q., Cui F.Z. (2012) Biocompatibility and toxicity of nanoparticles and nanotubes. J. Nanomater. 2012: 19.

Li Y., Hong Y.T., Luo D. (2005) Multiplexed detection of pathogen DNA with DNA-based fluorescence nanobarcodes. Nature Biotechnol. 23: 885-889. 
Li Y., Hu Y., Peng S., Lu G., Li S. (2009) Synthesis of CdS nanorods by an ethylenediamine assisted hydrothermal method for photocatalytic hydrogen evolution. J. Phys. Chem. C 113: 9352-9358.

Lian P., Zhu X., Liang S., Li Z., Yang W., Wang H. (2010) Large reversible capacity of high quality graphene sheets as an anode material for lithium-ion batteries. Electrochim. Acta 55: 3909-3914.

Lin M.T, Occhialini A., Andralojc P.J., Parry M.A., Hanson M.R. (2014) A faster Rubisco with potential to increase photosynthesis in crops. Nature 513: 547-550.

Linglan M., Chao L., Chunxiang Q., Sitao Y., Jie L., Fengqing G., Fashui H. (2008) Rubisco activase mRNA expression in spinach: modulation by nanoanatase treatment. Biol. Trace Elem. Res. 122(2): 168-178.

Liou T.H., Wu S.J. (2010) Kinetics study and characteristics of silica nanoparticles produced from biomass-based material. Ind. Eng. Chem. Res. 49: 8379-8387.

Lital Y., Nickolas J.T., McNeill V.F. (2010) Ultrafine particle emissions: Comparison of waste- to-energy with coal and biomass-fired power plants Columbia University pp. 1-22.

Liu C.G., Liu M., Li F., Cheng H.M. (2008) Frequency response characteristic of single-walled carbon nanotubes as supercapacitor electrode material. Appl. Phys. Lett. 92: 143108.

Liu C., Li F., Ma L.P., Cheng H.M. (2010) Advanced materials for energy storage. Adv. Mater. 22: 28-62.

Liu D., Zhang Y., Sun X., Chang P.R. (2014) Recent advances in bio-sourced polymeric carbohydrate/nanotube composites. J. Appl. Polymer Sci. 131: 12.

Liu R., Lal R. (2015) Potentials of engineered nanoparticles as fertilizers for increasing agronomic productions. Sci. Total Environ. 514: 131-139.

Liu J., Cao G., Yang Z., Wang D,, Dubois D., Zhou X., Graff G.L., Pederson L.R., Zhang J.G. (2008) Oriented nanostructures for energy conversion and storage. Chem. Sus. Chem. 1: 676-697.

Long Z., Ji J,.Yang K., Lin D., Wu F. (2012) Systematic and quantitative investigation of the mechanism of carbon nanotubes' toxicity toward Algae. Environ. Sci. Technol. 46: 8458-8466.

Lopez-Moreno M.L., De La Rosa G., Hernandez-Viezcas J.A., Castillo-Michel H., Botez C.E., Peralta-Videa J.R., GardeaTorresdey J.L. (2010) Evidence of the differential biotransformation and genotoxicity of $\mathrm{ZnO}$ and $\mathrm{CeO} 2$ nanoparticles on soybean (Glycine max) plants. Environ. Sci. Technol. 44: 7315-7320.

Luo B., Liu S., Zhi L. (2012) Chemical approaches toward graphene-based nanomaterials and their applications in energy-related areas. Small 8: 630-646.

Ma X., Geiser-Lee J., Deng Y., Kolmakov A. (2010) Interactions between engineered nanoparticles (ENPS) and plants: phytotoxicity, uptake and accumulation. Sci. Total Environ. 408(16): 3053-3061.

Malato S., Blanco J., Caceres J., Fernandez A.R., Aguera A., Rodriguez A. (2002) Photocatalytic treatment of water- solouble esticides by photo-Fenton and $\mathrm{Tio}_{2}$ using solar energy. Catal. Today. 76: 209-220.

Mani M.K., Viola G., Reece M.J., Hall J.P., Evans S.L. (2014) Fabrication of carbon nanotube reinforced iron based magnetic alloy composites by spark plasma sintering. J. Alloys Comp. 601: 146-153.

Maximous N., Nakhla G., Wong K., Wan W. (2010) Optimization of $A 1(2) O(3) / P E S$ membranes for wastewater filtration. Sep. Purif. Technol. 73: 294-301.

Mazumder V., Chi M., More K.L., Sun S. (2010) Core/shell $\mathrm{Pd} / \mathrm{FePt}$ nanoparticles as an active and durable catalyst for the oxygen reduction reaction. J. Am. Chem. Soc. 132: 7848-7849.

McLamore E.S., Diggs A., Marzal P.C., Shi J., Blakeslee J.J., Peer W.A., Mur D.M. (2010) Non-invasive Quantification of Endogenous Root Auxin Transport using microsensor technique. Plant J. 63: 1004-1016.

Momin J.K., Jayakumar C., Prajapati J.B. (2013) Potential of nanotechnology in functional foods. Emirates J. Food Agricult. 25(1): 10-19.

Mousavi S.R., Rezaei M. (2011) Nanotechnology in Agriculture and Food Production. J. Appl. Environ. Biol. Sci. 1(10): 414-419.

Nam J.M., Thaxton C.S., Mirkin C.A. (2003) Nanoparticlebased bio-bar codes for the ultrasensitive detection of proteins. Science 301: 1884-1886.

Niederberger M. (2007) Nonaqueous sol-gel routes to metal oxide nanoparticles. Acc. Chem. Res. 40: 793-800.

Noji T., Kamidaki C., Kawakami K., Shen J.R., Kajino T., Fukushima Y., Sekitoh T., Itoh S. (2011) Photosynthetic oxygen evolution in mesoporous silica material: adsorption of photosystem II reaction center complex into $23 \mathrm{~nm}$ nanopores in SBA. Langmuir 27(2): 705-713.

Novoselov K.S., Geim A.K., Morozov S.V., Jiang D., Zhang Y., Dubonos S.V., Grigorieva I.V., Firsov A.A. (2004) Electric field effect in atomically thin carbon films. Science 306: 666-669.

Orimo S., Nakamori Y., Eliseo J.R., Züttel A., Jensen C.M. (2007) Complex hydrides for hydrogen storage. Chem. Rev. 107: 4111-4132.

Osterfeld S.J., Yub H., Gaster R.S., Caramuta S., Xu L., Han S.J., Hall D.A., Wilson R.J., Sun S., White R.L., et al. (2008) Multiplex protein assays based on real-time magnetic nanotag sensing. Proc. Natl. Acad. Sci. USA 105: 20637-20640.

Pendergast M.T.M., Nygaard J.M., Ghosh A.K., Hoek E.M.V. (2010) Using nanocomposite materials technology to understand and control reverse osmosis membrane compaction. Desalinatio 261: 255-263.

Perea-de-Lugue A., Rubiales D. (2009) Nanotechnology for parasitic plant control. Pest Manag. Sci. 65: 540-545.

Philip G.C., Keith B., Masa I., Zettl A. (2000) Extreme oxygen sensitivity of electronic properties of carbon nanotubes. Science 287: 1801-1804.

Pocket K. (2011) No. 39. Nanotechnology in Agriculture International Service for the acquisition of agribiotech 
acquisitions. http://www.isaaa.org/resources/publications/ pocketk/39/default.asp.

Prasad R., Kumar V., Kumar M. (2017) Nanotechnology: food and environmental paradigm, Springer. 198pp.

Qiao Y., Li C.M. (2011) Nanostructured catalysts in fuel cells. J. Mater. Chem. 21: 4027-4036.

Qu L., Liu Y., Baek J.B., Dai L. (2010) Nitrogen-doped graphene as efficient metal-free electrocatalyst for oxygen reduction in fuel cells. ACS Nano. 4: 1321-1326.

Qu X., Alvarez P.J., Li Q. (2013a) Applications of nanotechnology in water and wastewater treatment. Water Res. 47: 3931-3946.

Qu X.L., Brame J., Li Q., Alvarez J.J.P. (2013b) Nanotechnology for a safe and sustainable water supply: enabling in tegrated water treatment and reuse. Acc. Chem. Res. 46: 834-843.

Raliya R., Tarafdar J.C. (2013) ZnO nanoparticle biosynthesis and its effect on phosphorous-mobilizing enzyme secretion and gum contents in cluster bean (Cyamopsis tetragonoloba L.). Agric. Res. 2: 48-57.

Ravishankar R.V., Jamuna B.A. (2011) Nanoparticles and their potential application as antimicrobials. [in:] Science against microbial pathogens: communicating current research and technological advances. Ed. A. Méndez-Vilas. Microbiol. Ser. 3(1): 197-209.

Rico C.M., Hong J., Morales M.I., Zhao L., Barrios A.C., Zhang J.Y., Peralta-Videa J.R., Gardea-Torresdey J.L. (2013) Effect of cerium oxide nanoparticles on rice: $A$ study involving the antioxidant defense system and in vivo fluorescence imaging. Environ. Sci. Technol. 47: 5635-5642.

Rosi N.L., Eckert J., Eddaoudi M., Vodak D.T., Kim J., O’Keeffe M., Yaghi O.M. (2003) Hydrogen storage in microporous metal-organic frameworks. Science 300: 1127-1129.

Rudramurthy G.R.. Swamy M.K., Sinniah U.R., Ghasemzadeh A. (2016) Nanoparticles: alternatives against drug-resistant pathogenic microbes. Molecules 21: 836.

Sabir S., Arshad M., Chaudhari S.K. (2014) Zinc oxide nanoparticles for revolutionizing agriculture: synthesis and applications. Sci. World J. 2014: 1-8.

Salama H.M.H. (2012) Effects of silver nanoparticles in some crop plants, common bean (Phaseolus vulgaris L.) and corn (Zea mays L.) Int. Res. J. Biotech. 3(10): 190-197.

Sariciftci N.S., Smilowitz L., Heeger A.J., Wudl F. (1992) Photoinduced electron transfer from a conducting polymer to buckminsterfullerene. Science 258: 1474-1476.

Savithramma N., Ankanna S., Bhumi G. (2012) Effect of nanoparticles on seed germination and seedling growth of Boswellia ovalifoliolata an endemic and endangered medicinal tree taxon. Nano Vision. 2: 61-68.

Sekhon B.S. (2014) Nanotechnology in agri-food production: an overview. Nanotechnol. Sci. Appl. 7: 31-53.

Shah V., Belozerova I. (2009) Influence of metal nanoparticles on the soil microbial community and germination of lettuce seeds. Water Air Soil Pollut. 197: 143-148.

Sharma Y.C., Srivastava V., Singh V.K., Kaul S.N., Weng C.H. (2009) Nano-adsorbents for the removal of metallic pollu- tants from water and wastewater. Environ. Technol. 30: 583-609.

Sharma P., Bhatt D., Zaidi M.G., Saradhi P.P., Khanna P.K., Arora S. (2012) Silver nanoparticle mediated enhancement in growth and antioxidant status of Brassica juncea. Appl. Biochem. Biotechnol. 167: 2225-2233.

Shaw A.K., Ghosh S., Kalaji H.M., Bosa K., Brestic M., Zivcak M., Hossain Z. (2014) Nano-CuO stress induced modula tion of antioxidative defense and photosynthetic performance of syrian barley (Hordeum vulgare L.). Environ. Exp. Bot. 102: 37-47.

Siddiqui M.H., Al-Whaibi M.H., Faisal M., Al Sahli A.A. (2014) Nano-silicon dioxide mitigates the adverse effects of salt stress on Cucurbita pepo L. Environ. Toxicol. Chem. 33(11): 2429-2437.

Siddiqui M.H., Al-Whaibi M.H.., Firoz M., Al-Khaishany M.Y. (2015) Role of nanoparticles in plants. [in:] Nanotechnology and plant sciences: nanoparticles and their impact on plants. Ed. Siddiqui M.H., Al-Whaibi M.H., Mohammad F. Springer: 19-35.

Siddiqui M.H., Mohammad F., Khan M.M.A., M.H. Al-Whaibi (2012) Cumulative effect of nitrogen and sulphur on Brassica juncea L. genotypes under $\mathrm{NaCl}$ stress. Protoplasma 249: 139-153.

Singh A., Singh N.B., Hussain I., Singh H., Singh S.C. (2015) Plant-nanoparticle interaction: an approach to improve agricultural practices and plant productivity. Int. J. Pharmaceut. Sci. Inv. 4(8): 25-40.

Somani P.R., Somani S.P., Flahaut E., Umeno M. (2007) Improving the photovoltaic response of a poly(3-octylthiophene)/n-Si heterojunction by incorporating double- walled carbon nanotubes. Nanotechnology 18: 18570-18571.

Sondi I., Salopek-Sondi B. (2004) Silver nanoparticles as antimicrobial agent: a case study on E. coli as a model for Gram negative bacteria. J. Colloid Interface Sci. 275: 177-182.

Suriyaprabha R., Karunakaran G., Yuvakkumar R., Rajendran V., Kannan N. (2012) Silica nanoparticles for increased silica availability in maize (Zea mays L.) seeds under hydroponic conditions. Curr. Nanosci. 8: 902-908.

Suppan S. (2013) Nanomaterials in soil: our future food chain? Minneapolis, MN: Institute for Agriculture and Trade Policy. https://www.researchgate.net/publication.

Syu Y.Y., Hung J.H., Chen J.C., Chuang H.W. (2014) Impacts of size and shape of silver nanoparticles on Arabidopsis plant growth and gene expression. Plant Physiol. Biochem. 83: 57-64.

Taha R.A. (2016) Nanotechnology and its application in agriculture. Adv. Plants Agricult. Res. 3(2): 00089

Tereshchenko N., Zmeeva O., Makarov B., Kravets A., Svetlichny V., Lapin I., Zotikova A., Petrova L., Yunusova T. (2017) The influence of silicon oxide nanoparticles on morphometric parameters of monocotyledons and dicotyledons in soil and climatic conditions of Western Siberia, as well as on microbiological soil properties. BioNanoSci. 7(4): 703-711.

Theron J., Eugene Cloete T., de Kwaadsteniet M. (2010) Current molecular and emerging nanobiotechnology ap- 
proaches for the detection of microbial pathogens. Crit. Rev. Microbiol. 36: 318-339.

Tiwari P.M., Vig K., Dennis V.A., Singh S.R. (2011) Functionalized gold nanoparticles and their biomedical applications. Nanomaterials 1: 31-63.

Touhami A. (2014) Biosensors and Nanobiosensors: Design and Applications (ch-15 book-nanomedicine).

Vannini C., Domingo G., Onelli E., Prinsi B., Marsoni M., Espen L., Bracale M.( 2013) Morphological and proteomic responses of Eruca sativa exposed to silver nanoparticles or silver nitrate. PLoS ONE 8: e68752. doi: 10.1371/ journal.pone.0068752.

Vikesland P.J., Wigginton K.R. (2010) Nanomaterial enabled biosensors for pathogen monitoring: a review. Env. Sci. Technol. 44: 3656-3669.

Wang J. (2008) Electrochemical Glucose Biosensors. Chem. Rev. 108: 814-825.

Wang J.X., Inada H., Wu L., Zhu Y., Choi Y., Liu P., Zhou W.P, Adzic R.R. (2009) Oxygen reduction on well-defined coreshell nanocatalysts: particle size, facet, and Pt shell thickness effects. J. Am. Chem. Soc. 131: 17298-17302.

Wang P., Lombi E., Zhao F.J., Kopittke P.M. (2016) Nanotechnology: a new opportunity in plant sciences. Trends Plant Sci. 21: 699-792.

Wang Q., Ma X., Zhang W., Pei H., Chen Y. (2012) The impact of cerium oxide nanoparticles on tomato (Solanum lycopersicum L.) and its implications for food safety. Metallomics 4(10): 1105-1112.

Wang X., Ding Y., Summers C.J., Wang Z.L. (2004) Large scale synthesis of six-nanometer-wide $\mathrm{ZnO}$ nanobelts. J. Phys. Chem. B. 108(26): 8773-8777.

Whitesides G.M. (2005) Nanoscience, nanotechnology, and chemistry. Small 1: 172-179.

Wu H., Zhang Z. (2011) High photo electrochemical water splitting performance on nitrogen doped double-wall $\mathrm{TiO}_{2}$ nanotube array electrodes. Int. J. Hydrogen Energy 36: 13481-13487.

Wu L.F., Ritchie S.M.C. (2008) Enhanced dechlorination of trichloroethylene by membrane-supported Pd-coated iron nanoparticles. Environ. Prog. 27: 218-224.

Yin L., Colman B.P., McGill B.M., Wright J.P., Bernhardt E.S. (2012) Effects of silver nanoparticle exposure on germination and early growth of eleven wetland plants. PLoS ONE 7: $1-7$.
Yu C., Zhang L., Shi J., Zhao J., Gao J., Yan D. (2008) A simple template-free strategy to synthesize nanoporous manganese and nickel oxides with narrow pore size distribution, and their electrochemical properties. Adv. Funct. Mater. 18: 1544-1554.

Yu D.S., Nagelli E., Du F., Dai L.M. (2010 ) Metal-free carbon nanomaterials become more active than metal catalysts and last longer. J. Phys. Chem. Lett. 1: 2165-2173.

Zhang J., Li C.M. (2012) Nanoporous metals: fabrication strategies and advanced electrochemical applications in catalysis, sensing and energy systems. Chem. Soc. Rev. 41: 7016-7031.

Zhao X., Sánchez B.M., Dobson P.J., Grant P.S. (2011) The role of nanomaterials in redox-based super capacitors for next generation energy storage devices. Nanoscale 3: 839-855.

Zheng L., Hong F., Lu S., Liu C. (2005) Effect of nano-TiO(2) on strength of naturally aged seeds and growth of spinach. Biol. Trace Elem. Res. 105: 83-91.

Zheng J., Birktoft J.J., Chen Y., Wang T., Sha R., Constantinou P.E., Ginell S.L., Mao C., Seeman N.C. (2009) From molecular to macroscopic via the rational design of a self-assembled 3D DNA crystal. Nature 461: 74-77.

Zhi M., Xiang C., Li J., Li M., Wu N. (2013) Nanostructured carbon-metal oxide composite electrodes for supercapacitors: a review. Nanoscale 5: 72-88.

Zhong C.J., Luo J., Fang B., Wanjala B.N., Njoki P.N., Loukrakpam R., Yin J.(2010) Nanostructured catalysts in fuel cells. Nanotechnology 21: 062001.

Zinjarde S.S. (2012) Bio-inspired nanomaterials and their applications as antimicrobial agents. Chronic. Young Sci. 3: 74-81.

Zukalová M., Zukal A., Kavan L., Nazeeruddin M.K., Liska P., Grätzel M. (2005) Organized mesoporous TiO2 films exhibiting greatly enhanced performance in dye-sensitized solar cells. Nano. Lett. 5: 1789-1792.

Zuttel A., Sudan P., Mauron P., Kiyobayashi T., Emmenegger C., Schlapbach L. (2002) Hydrogen storage in carbon nanostructures. Int. J. Hydrogen Energy 27: 203-212. 